\title{
In vitro percutaneous penetration of methyl-parathion from a commercial formulation through the human skin
}

\author{
P Sartorelli, C Aprea, R Bussani, M T Novelli, D Orsi, G Sciarra
}

\begin{abstract}
Objective-To compare in vitro percutaneous absorption of methyl-parathion dissolved in an acetone vehicle and in the form of a commercial formulation. Methods-Penetration through the human skin was measured in Franz diffusion cells with full thickness skin from a human cadaver as the membrane. The two tailed non-parametric Mann-Whitney $U$ test was used to compare the cumulative diffusion of methyl-parathion in the receptor fluid of the cells at various time intervals.

Results-In vitro skin penetration of methyl-parathion was significantly higher with the commercial formulation. The percentage of the applied dose absorbed after 24 hours was $5.20 \% v 1.35 \%$. The mean lag time was $<8$ hours.

Conclusion-Assessments of uptake and internal dose after exposure to pesticides should be based on the commercial products rather than active ingredients, because of the crucial role of the vehicle, as shown in this study.
\end{abstract}

(Occup Environ Med 1997;54:524-525)

Keywords: percutaneous absorption; methyl-parathion; human skin

The main route of human exposure to pesticides is through skin contamination. It is therefore important to establish the percutaneous absorption of these chemicals after topical exposure in humans. It is well known that percutaneous penetration of xenobiotics is influenced by the vehicle used. ${ }^{12}$ Evaluation of risk assessment on percutaneous absorption should

Accepted 23 January 1997 take these effects into consideration. Parathion (PA) is a widely used organophosphorus insecticide. Surveys have shown that most cases of poisoning among farmers handling PA involve percutaneous absorption. ${ }^{3}$ Feldmann and Maibach, ${ }^{4}$ found percutaneous absorption of ${ }^{14} \mathrm{C}$-PA after application in a small amount of acetone to the forearm of human volunteers. In vivo and in vitro studies have shown a faster absorption rate for PA than for malathion. ${ }^{4-6}$ The influence of different vehicles on the dermal penetration of PA has been studied in pigs: $15 \%-30 \%$ of dermally applied PA was absorbed when given in dimethyl sulphoxide or octanol, but only $4 \%-5 \%$ when given in Macrogol $400 .^{7}$ Environmental factors, such as high relative humidity and temperature, can also increase PA penetration.

This study compares in vitro absorption of methyl-parathion (MPA) dissolved in an acetone vehicle and in the form of a commercial formulation.

\section{Methods}

Percutaneous penetration measurements were made in a static diffusion cell system (Crown

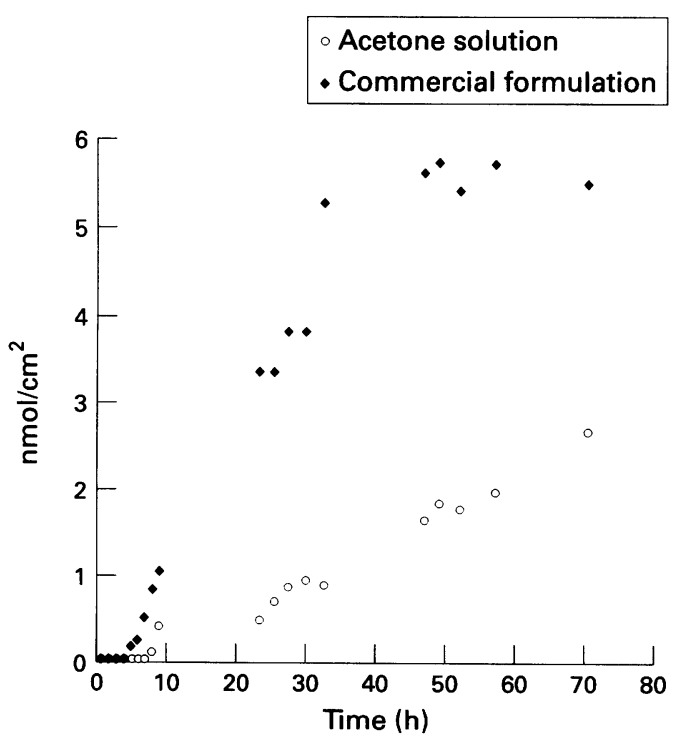

Cumulative penetration of methyl-parathion through human skin ( $\mathrm{nmol} / \mathrm{cm}^{2}$ membrane surface) in relation to time for acetone solution and a commercial formulation. 
Glass, Sommerville, NJ, USA), with saline solution, $4 \%$ bovine serum albumin, and gentamycin sulphate as the receptor. This fluid was chosen to enhance the solubility of MPA in the diffusion cell receptor without damaging the integrity of the skin barrier. Full thickness skin from a human cadaver was used as the membrane after removing the subcutaneous fat. All skin samples, obtained from the abdomen of the same subject (a 60 year old white man without skin diseases), were previously frozen and stored for few days. The skin surface temperature was maintained at $32^{\circ} \mathrm{C}$ by heating blocks holding the cell with water at $37^{\circ} \mathrm{C}$.

In a group of three cells $51.07 \mathrm{nmol} / \mathrm{cm}^{2}$ MPA in $30 \mu \mathrm{l}$ acetone solution $(3.01 \mu \mathrm{mol} / \mathrm{ml})$ were deposited. This volume was sufficient to spread across the entire exposed surface, yet evaporate in less than a minute, as previously reported. ${ }^{9}$ In another three cells $64.26 \mathrm{nmol} /$ $\mathrm{cm}^{2}$ of MPA in $30 \mu \mathrm{l}$ of watered down commercial preparation $(0.5534 \mathrm{~g}$ of commercial formulation diluted in $100 \mathrm{ml}$ of water) were applied $\left(4.2 \mu \mathrm{mol} / \mathrm{ml} \mathrm{MPA}\right.$ in $99 \% \mathrm{H}_{2} \mathrm{O}$ with $0.4 \%$ xylene). The commercial formulation consisted of $20 \% \mathrm{MPA} \quad(90 \%$ pure methyl-parathion), about $5 \%$ dispersing agents, and $75 \%$ xylene. In each cell 19 samples were drawn over a 48 hour period to find the MPA concentrations. The concentration of MPA was measured by gas chromatography (Hewlett Packard 5890) with a capillary column and a nitrogen-phosphorus detector (NPD). The substance was extracted from the receptor fluid with hexane (LiChrosolv, MerckDarmstadt, Germany). The detection limit of the method for MPA was $0.004 \mathrm{nmol} / \mathrm{ml}$.

The results were expressed as the arithmetic mean of the cumulative diffusion of MPA (in $\mathrm{nmol} / \mathrm{cm}^{2}$ membrane surface) into the receptor fluid of both groups of cells at various time intervals. The two tailed non-parametric Mann-Whitney $U$ test was used to compare unpaired groups. Lag time values, steady state absorption rates, and percentages of the applied dose absorbed at 24 and 48 hours were calculated.

\section{Results}

The figure shows the cumulative penetration of MPA dissolved in an acetone solution and in the form of the commercial formulation in relation to time. The absorption rate of the commercial formulation decreased before 48 hours after deposition, reaching a plateau. In vitro skin penetration of methyl-parathion was significantly higher $(P<0.001)$ for the commercial formulation.

The table shows the lag time values, steady state absorption rates, and percentages of applied dose at 24 and 48 hours. The absorption rate mean values normalised for the concentration of compound applied (permeability constant $\mathrm{Kp}$ ), were higher for the commercial product than for MPA in acetone. Percutaneous penetration was also faster for the commercial product and had lower mean lag time values than for MPA in acetone. The mean lag times were $<8$ hours for MPA in acetone and $<4$ hours for MPA as a commercial product.

\section{Discussion}

Despite differences between the two models, the absorption percentages for MPA in acetone at 24 and 48 hours were similar to those obtained for PA in an acetone solution by Feldmann and Maibach ${ }^{4}$ in human volunteers (3.89\% at 24 hours and $6.53 \%$ at 48 hours). Besides the chemical diversity of the two formulations, the different methods of application and the different concentrations should be considered.

Both in acetone and the commercial formulation, MPA penetration reached a steady state in times shorter than the duration of a workshift. This poses a substantial risk because workers do not usually wash properly until the end of the shift. Washing, moreover, does not guarantee the end of percutaneous absorption, as cutaneous deposits of the substance may remain. The possibility that absorption continues after the end of exposure should be taken into account when evaluating the results of biological monitoring.

The flux of permeant is proportional to the partition coefficient of the permeant between the membrane and the external medium ${ }^{10}$ : the differences in lag time and absorption rate found can be attributed to the different affinity of the compound for the vehicles. Assessments of uptake and internal dose on exposure to pesticides should be based on the commercial products rather than active ingredients, because of the crucial role of the vehicle, as was shown in this study. Under certain agricultural working conditions, the various degrees of percutaneous absorption of pesticides in relation to the different formulations of commercial products available should be taken into account in evaluating chemical risk. If these variations are not taken into consideration, especially in the absence of accurate biological monitoring, absorption could be underestimated.

1 Twist JN, Zatz JL. Interaction of vehicles with model skin membranes in the permeation process. In: Bronaugh RL, Maibach HI, eds. Percutaneo

2 Bronaugh RL, Franz TJ. Vehicle effects on percutaneous absorption: in vivo and in vitro comparisons with human skin. Br f Dermatol 1986;115:1-11.

3 Shin JH, Wu ZQ, Wang YL, Zhang YX, Xue SZ, Gu XQ Prevention of acute parathion and demeton poisoning in farmers around Shanghai. Scand $f$ Work Environ Health 1985;11:49-54

4 Feldmann RJ, Maibach HI. Percutaneous penetration of some pesticides and herbicides in man. Toxicol Appl Pharmacol 1974;28:126-32.

5 Shah PV, Monroe RJ, Guthrie FE. Comparative rates of dermal penetration of insecticides in mice. Toxicol Appl Pharmacol 1981;59:414-23.

6 Chang SK, Williams PL, Dauterman WC, Riviere JE Percutaneous absorption, dermatopharmacokinetics and related biotransformation studies of carbaryl, lindane, related biotransformation studies of carbaryl, lindane, malathion, and parathion in

Toxicology 1994;91:269-80,
Gyrd Hansen N, Brimer L, Rasmussen F. Percutaneous absorption of organophosphorus insecticides in pigs. The absorption of organophosphorus insecticides in pigs. The
influence of different vehicles. $\mathcal{F}$ Vet Pharmacol Ther 1993;16:174-80.

8 Chang SK, Riviere JE. Percutaneous absorption of parathion in vitro in porcine skin: effects of dose, temperature, humidity, and perfusate composition on absorptive flux. Fundam Appl Toxicol 1991;17:494-504.

9 Franz TJ. Percutaneous absorption: on the relevance of in vitro data. F Invest Dermatol 1975;64:190-5.

10 Flynn GL. Physicochemical determinants of skin absorption. In: Gerrity TR, Henry CJ, eds. Principles of route-to-route extrapolation for risk assessment. New York: Elsevier, 1990:93-127. 